\title{
Hedging in the Results and Discussion Section of English Applied Linguistics Research Articles by Vietnamese and Foreign Writers
}

\author{
Thao Quoc Tran* \\ HUTECH University, Vietnam \\ Thiep Ba Tang \\ International School, Binh Duong City, Vietnam
}

\begin{abstract}
Hedging in academic writing in general and in research article (RA) in specific has a vital role in enabling writers to minimize their opposing claims and negotiate the meaning. Nevertheless, hedging can be different from one discipline to another and from culture to another. This study, therefore, aims at examining the deployment of hedges in the Results and Discussion (R-D) section of English Applied Linguistics (AL) RAs by Vietnamese writers and their foreign counterparts. Two corpora consisting of 30 RAs written by Vietnamese writers and the other 30 ones by foreign writers were collected. The results revealed that both Vietnamese and foreign writers deployed hedges in the R-D section of English AL RAs at a similar frequency. Moreover, they shared common senses of utilizing the hedges' types and functions in the R-D section of English AL RAs. This study has confirmed that the norms and practices of the AL, a soft science, were common among non-native English writers regardless of their culture-bound.
\end{abstract}

Index Terms—applied linguistics, Hedge, non-native English writer, results and discussion, soft science

\section{INTRODUCTION}

Hedges have been deemed as important devices that help writers to show their viewpoints in academic writing in general and in research articles (RAs) in specific. When writers employ hedges in their writing, they can integrate their assertions and argumentation through their writing (Hyland, 1998). Moreover, hedges can help researchers to defend their viewpoints and still help them use the probability and certainty to their claims (e.g., Lakoff, 1972; Hyland, 2000, 2005).

Within the academic research, the presentation of the content of RAs varies from one discipline or discourse community to another to suit the depiction of the subject matter and the audience basing on in accordance with the conformed methods and ideology (Bazeman, 1988). Regarding the field of English Applied Linguistics (AL), RAs usually consist of five main components, namely introduction, literature review, methodology, results and discussion (R-D) and conclusion. Among these components, the R-D section in RAs is considered one of the most pivotal parts as it is the place where writers can "highlight findings and situate them in a context of a wider body of knowledge by relating the results to the work of others" (Hyland, 1998, p. 33). Additionally, it is the R-D section where writers can claim how the findings can contribute to the body to literature (Basturkmen, 2012), and where writers tend to employ hedges the most (Salager-Meyer, 1994).

Within the context of Vietnam, English is used as a foreign language, which can cause Vietnamese writers difficulties in deploying appropriate hedges in their RAs. Therefore, Vietnamese writers may use hedges in their RAs differently from native English ones. What is more, it is noticed that prior studies have failed to scrutinize the hedges' use and functions in the R-D section of the English AL RAs by Vietnamese writers although many studies analyzing the utilization of hedges in RAs have been found. Given the aforementioned reasons, this study attempts to scrutinize the deployment of hedges in the R-D section of English AL RAs by Vietnamese writers and their foreign counterparts. The questions to be addressed are formed as follows:

1. How are hedges deployed in the R-D section of English AL RAs by Vietnamese writers and their foreign counterparts?

2. How do hedges function in the R-D section of English AL RAs by Vietnamese writers and their foreign counterparts?

\section{LITERATURE REVIEW}

\footnotetext{
* Corresponding author: Thao Quoc Tran, email: tq.thao @ hutech.edu.vn
} 
The term hedge has been variously defined. Lakoff (1972) defines hedges as "words whose meanings involved fuzziness -words whose job is to make things fuzzier or less fuzzy" (p. 471). Fuzziness can enable writers or speakers to avoid losing face in confusing situations (e.g., Salager-Meyer, 1994; Tran \& Duong, 2013), and it can provide readers or listeners with the chances for different interpretations (Crompton, 1997). In the similar vein, Hyland (1998) states that hedges are "the means by which writers can present a proposition as an opinion rather than a fact: items are only hedges in their epistemic sense, and only when they mark uncertainty" (p. 5). Sharing the same view, Yagiz and Demir (2014) delineate hedges as a type of tentative language to obtain from any certainty or to mitigate the claims or propositions avoiding negative criticism from readers or research partners.

Many researchers (e.g., Salager-Meyer, 1994; Hyland, 1998a, 2000; Varttala, 2001; Hinkel, 2005) have proposed different categories of hedges. Significantly, Salager-Meyer's (1994) classification of hedges includes seven categories (1-Modal auxiliary verbs; 2-Modal lexical verbs; 3-Adjectival, nominal, and adverbial modal phrases; 4-Approximators of degree, quantity, frequency, and time; 5-Introductory phrases; 6-If clauses; 7-Compound hedges). Meanwhile, Varttala (2001) has classified hedges in eight categories (1-Modal auxiliary verbs; 2-Full verbs; 3-Adverbs; 4Adjectives; 5-Nouns; 6-Clausal elements; 7-Questions; 8-Others. Differently, Farrokhi and Emami (2008) compiled five types of hedges (1-modal verbs; 2-lexical verbs; 3-adverbs;4- adjectives; 5-nouns).

As hedges have various types, they have different functions. Salager-Meyer (1994) classified the functions of hedges as Shields (e.g., to appear, can, could), Approximators of degree, time and frequency (e.g., approximately, generally, usually), Authors' personal doubt and direct involvement (e.g., I believe, to our knowledge), Emotionally- charged intensifiers (e.g., extremely difficult/interesting, of particular importance), and Compound hedges (e.g., it could be suggested, it would seem likely). In another aspect, Hyland (1998a) has created a clear model of hedges called the polypragmatic model by dividing hedges into two main functions: content-oriented including two sub-functions: accuracyoriented (Attributes hedges \& Reliability hedges) and writer-oriented and reader-oriented.

For the purposes of this study, hedges can be seen as lexical devices used to signal the writers' lack of confidence and mitigate their certainty about or reduce their commitment to a proposition. Based on Salager-Meyer's (1994), Varttala's (2001) and Farrokhi and Emami's (2008) classification of hedges, hedges can be classified in Modal auxiliaries, Epistemic lexical verbs, Epistemic adjectives, Epistemic adverbs, Nouns, and Others (e.g., phrases, if clauses). Hyland's (1998a) taxonomy in function is used in this study, encompassing content-oriented with two subfunctions: accuracy-oriented (Attributes hedges \& Reliability hedges) and writer-oriented, and reader-oriented. Accuracy-oriented hedges are used to present information, points of view as precisely, fully and objectively as possible; writer-oriented hedges to shield themselves from the oppositions by limiting the personal commitments; and readeroriented hedges are to create good relationships and facilitate the effective communication between writers and readers.

Several studies (e.g., Farrokhi \& Emami, 2008; Nasiri, 2012; Tran \& Duong, 2013; Nguyen, 2018) have been carried out to seek for the differences in native English and non - native English writers' use of hedges in academic writing. Hyland (2008) conducted a study of a corpus consisting of 240 RAs from eight disciplines. The results showed that the number of hedges and boosters in the soft fields appears more than that in the hard fields. Among eight disciplines, writers in AL used hedges and boosters most. Farrokhi and Emami (2008) analyzed the utilization of hedges and boosters in four main sections (Abstract, Introduction, Discussion, \& Conclusion) of 10 Electrical Engineering and 10 AL RAs by native and non-native English writers. The results indicated that native English writers used hedges and boosters differently from their non-native English counterparts. Nasiri (2012) did a study on the frequency of hedges used in the field of Civil Engineering between Americans and Iranians. The study focused on two chapters Introduction and Discussion in 20 RAs, and the findings showed that both American and Iranian writers used hedges in RAs similarly. Tran and Duong (2013) analyzed the use of hedges in the R-D section of 30 RAs in English AL and Chemical Engineering. They found out that writers in the field of English AL used hedges more frequently than those in Chemical Engineering. Nguyen and Nguyen (2015) conducted a study of American and Vietnamese celebrities' hedges in responses to questions in interviews. They collected data from 96 online interviews from American and Vietnamese celebrities. The researchers found that out of five categories under investigation, quality hedges were most frequently used with a rather high rate. Nguyen (2018) analyzed Vietnamese writers and native English writers' use of hedges in RAs. Two corpora from 50 RAs in AL written by Vietnamese writers and 50 RAs written by native English writers were designed. The findings revealed that the frequency of occurrence of hedges in RAs written by Vietnamese writers was relatively lower than that of native English writers because of the divergence of culturally different backgrounds. In brief, many studies on hedges in different disciplines have been found. However, the studies on the use of hedges in English AL RAs between Vietnamese writers and non-native English ones are still rare. Regarding the context of Vietnam, it is assumed that Vietnamese writers with their own characteristics and culture-bound may write English AL RAs differently from other writers. This study, therefore, attempts to analyze Vietnamese writers and their foreign counterparts' deployment of hedges in the R-D section of English AL RAs.

\section{Methodology}

\section{A. Materials}


There were two corpora: One corpus consisting of 30 R-D sections (total words: 62,545) of English AL RAs written by Vietnamese writers, and one corpus with 30 R-D sections (total words: 57,300) of English AL RAs written by foreign writers who were non-native English speakers. All selected 60 RAs were published from 2012 to 2020 . The articles were selected from journals in AL or related to linguistics.

\section{B. Procedures for Data Collection and Analysis}

To collect data, all the materials for this study were selected according to the following criteria: (1) The RAs must be published from 2012 to 2020; (2) The R-D section must be extracted from English AL RAs; (3) The R-D section of each article must have the length between 1,500 words and 2,500 words. As for data analysis, lists of hedges and their functions adapted from Hyland (1998), Salager-Meyer (1997), Varttala (2001), and Farrokhi and Emami (2008) were used. The software AntConc version 3.5.8, was used to identify hedges. All the RAs were coded as FW1, FW2 to FW30 for RAs written by foreigners and VW1, VW2 to VW30 for RAs written by Vietnamese. To assure the validity and reliability of the data analysis, inter-rating was employed. Two other researchers in the field of English AL were invited for re-analyzing five randomly chosen pieces of data. The accepted convergent results were set at $95 \%$.

\section{RESUlts AND Discussion}

\section{A. Results}

\section{The Deployment of Hedges in the R-D Section of English AL RAs Written by Vietnamese and Foreign Writers}

As seen in Table 1, the frequency of hedges in the R-D section of English AL RAs was 1,452 out of 62,545 words (accounting for $2.32 \%$ per 1,000 words) for Vietnamese writers and 1374 out of 58,300 words (making up $2.40 \%$ per 1,000 words) for foreign ones. This means that both Vietnamese and foreign writers used hedges in the R-D section of English AL RAs at a similar frequency.

TABLE 1

FREQUENCY OF HEDGES IN THE R-D SECTION OF ENGLISH AL RAS WRITTEN BY VIETNAMESE WRITERS AND FOREIGN WRITERS

\begin{tabular}{|c|c|c|c|c|c|c|}
\hline Types & \multicolumn{3}{|c|}{$\begin{array}{c}\text { Corpus - Vietnamese writers } \\
(62,545 \text { words })\end{array}$} & \multicolumn{3}{c|}{$\begin{array}{c}\text { Corpus - Foreign writers } \\
(57,300 \text { words })\end{array}$} \\
\hline & $\mathrm{F}$ & $\%$ & $\begin{array}{c}\% \text { per 1,000 } \\
\text { words }\end{array}$ & $\mathrm{F}$ & $\%$ & $\%$ per 1,000 words \\
\hline Hedges & 1452 & 80.35 & 2.32 & 1374 & 82.42 & 2.40 \\
\hline
\end{tabular}

\section{Hedge Categories in the R-D Section of English AL RAs Written by Vietnamese Writers and Their Foreign Counterparts}

The results in Table 2 reveal that both Vietnamese and foreign writers used hedge categories in their R-D sections of RAs relatively similarly. They employed Modal auxiliaries the most with $.85 \%$ and $.76 \%$ per 1,000 words respectively, followed by Epistemic Lexical verbs (.50\% per 1,000 words vs. .55\% per 1,000 words) and Epistemic Adjectives (.30\% per 1,000 words vs. $.38 \%$ per 1,000 words). Additionally, they also deployed Epistemic Adverbs (.18\% per 1,000 words vs. . $20 \%$ per 1,000 words) and Others (.31\% per 1,000 words vs. $.35 \%$ per 1,000 words) in their R-D sections of RAs in a similar way. It is, nevertheless, noticed that Vietnamese writers utilized more Nouns in their R-D sections of RAs than their foreign counterparts (.24\% per 1,000 words vs. .7\% per 1,000 words).

TABLE 2

Distribution OF HEDGE CATEGORIES IN THE R-D SECTION OF ENGLISH AL RAS WRITTEN By VIETNAMESE AND FOREIGN WRITERS

\begin{tabular}{|c|c|c|c|c|c|c|}
\hline \multirow[t]{2}{*}{ CATEGORY } & \multicolumn{3}{|c|}{$\begin{array}{l}\text { Corpus - Vietnamese writers } \\
(62,545 \text { WORDS })\end{array}$} & \multicolumn{3}{|c|}{$\begin{array}{l}\text { Corpus - Foreign writers } \\
(57,300 \text { WORDS })\end{array}$} \\
\hline & $\mathrm{F}$ & $\%$ & $\%$ PER 1,000 WORDS & $\mathrm{F}$ & $\%$ & $\%$ PER 1,000 WORDS \\
\hline MODAL AUXILIARIES & 491 & 33.82 & .76 & 487 & 35.44 & .85 \\
\hline EPISTEMIC LEXICAL VERBS & 315 & 21.69 & .50 & 317 & 23.07 & .55 \\
\hline EPISTEMIC ADVERBS & 114 & 7.85 & .18 & 114 & 8.30 & .20 \\
\hline EPISTEMIC ADJECTIVES & 186 & 12.81 & .30 & 216 & 15.72 & .38 \\
\hline NoUNS & 149 & 10.26 & .24 & 42 & 3.06 & .07 \\
\hline OTHERS & 197 & 13.57 & .31 & 198 & 14.41 & .35 \\
\hline TOTAL & 1452 & 100 & 2.29 & 1374 & 100 & 2.40 \\
\hline
\end{tabular}

\section{Vietnamese Writers and Their Foreign Counterparts}

Table 3 illustrates the distribution of the hedge functions in the R-D section of English AL RAs written by Vietnamese and foreign writers. It is seen that the function of Reliability hedges was most employed by Vietnamese writers $(7.91 \%$ per 1,000 words) and foreign writers (8.64\% per 1,000 words), followed by Writer-oriented hedges (7.24\% per 1,000 words vs. $7.38 \%$ per 1,000 words) and Attribute hedges (5.00\% per 1,000 words vs. $6.07 \%$ per 1,000 words). The least used function of hedges belongs to Reader-oriented hedges (Vietnamese writers: $.30 \%$ per 1,000 
words; foreign writers: $.40 \%$ per 1,000 words). Overall, both Vietnamese and foreign writers tended to employ the functions of hedges in a similar way.

TABLE 3

HEDGE Functions In THE R-D SECTION OF ENGLISH AL RAS WRITTEN BY VIETNAMESE WRITERS AND THEIR FOREIGN COUNTERPARTS

\begin{tabular}{|l|l|l|l|l|l|l|}
\hline \multirow{2}{*}{ FUNCTIONS } & \multicolumn{2}{l}{$\begin{array}{l}\text { CORPUS - VIETNAMESE WRITERS } \\
(62,545 \text { WORDS })\end{array}$} & \multicolumn{2}{l|}{$\begin{array}{l}\text { CORPUS - FOREIGN WRITERS } \\
(57,300 \text { WORDS })\end{array}$} \\
\hline & $\mathrm{F}$ & $\%$ & $\%$ PER 1,000 WORDS & F & $\%$ & $\%$ PER 1,000 WORDS \\
\hline ATTRIBUTE & 313 & 24.45 & 5.00 & 348 & 27.00 & 6.07 \\
\hline RELIABILITY & 495 & 38.67 & 7.91 & 495 & 38.40 & 8.64 \\
\hline WRITER-ORIENTED & 453 & 35.39 & 7.24 & 423 & 32.82 & 7.38 \\
\hline READER-ORIENTED & 19 & 1.49 & .30 & 23 & 1.78 & .40 \\
\hline TOTAL & 1,280 & 100 & 20.47 & 1,289 & 100 & 22.50 \\
\hline
\end{tabular}

\section{Accuracy-Oriented Hedges - Attribute Hedges}

The attribute hedges such as about, approximately, generally, quite, and so on are found in the R-D section of English AL RAs written by both Vietnamese and foreign writers. As seen the examples (1), and (2), both Vietnamese and foreign writers used attribute hedges to show the estimate value to avoid showing the precise figures or numbers which cannot be precisely idealized. These attribute hedges can help them to show their claims or propositions with acceptable degrees.

(1) "All participants in both groups had approximately similar performance on proficiency test and the obtained means and standard deviations of both groups were to some extent, similar." (FW 18)

(2) “Overall, Vietnam's forests contain about 800 tree, 60 bamboo and more than 1500 medicinal plant species.” (VW7)

\section{Accuracy-Oriented Hedges - Reliability Hedges}

The reliability hedges (e.g., may, possible, possibly, apparent, etc.) are used to help writers convey the reliability of their proposition or claims. The examples (3) and (4) indicate that Vietnamese and foreign writers tended to use reliability hedges may or could to acknowledge their uncertain knowledge in a proposition.

(3) "An adolescent will engage in social interaction in order to achieve particular goals, and some regulation strategy usage may be transferred across situations, from school to social interactions." (FW1)

(4) "However, it could be argued that the emphasis given to the researchers/authors by these Vietnamese writers through their preferred use of Discourse...." (VW26)

\section{Writer-Oriented Hedges}

Both Vietnamese and foreign writers tended to use writer-oriented hedges (e.g., epistemic lexical verbs, passive voice, agentless or impersonal subject, etc.) to shield themselves from the oppositions by limiting the personal commitments. In the example (5), the foreign writer employed appear, a tentative verb, for tentative approximation.

(5) "Regard to the second research question, learners appeared to be motivated to study the skills according to their weighting on the test." (FW3)

In the example (6), the foreign writer used seem as a main device or tool which helps him avoid personal proposition.

(6) "It seems that formal training did influence teachers' beliefs and their instructional practices." (FW15)

Vietnamese writers deployed the writer-oriented hedges to avoid personal responsibility for statements or limit the damage which may result from the categorical commitments in terms of passive voice forms, impersonal subjects or lexical verbs. The example (7) is as follows:

(7) "I thought that they understood everything, but in reality, there was something that they just didn't understand." (VW23)

\section{Reader-Oriented Hedges}

The example (8) shows that foreign writers employed reader-oriented hedges such as I think, it can be inferred that, we believe that, etc. to avoid conflicts in negotiation between writers and readers.

(8) 'It can be inferred that when the students' ability to use English for communication is limited, learning grammar seems to be more secure to deal with their linguistic limitation and to reduce their performance anxiety." (FW15)

\section{B. Discussion}

The results have unraveled some major findings. The first finding is that both Vietnamese and foreign writers used hedges in the R-D section of English AL RAs in terms of frequency in similar ways. This may show a common agreement among scholars in the field of English Al RAs known as the soft science. In another aspect, the writers (both Vietnamese and foreigners) of the analyzed RAs in this study could be non-native English writers, so there could be some limitations in their English language use. This finding is not in alignment with that of Farrokhi and Emami (2008) who conducted a study to explore the use of hedges and boosters by native and non-native writers in RAs of two disciplines of Electrical Engineering and English AL RAs and found that native English writers used more hedges than 
that of non-native English writers. This difference may result from the fact that native English writers have a higher level of English proficiency than their non-native English counterparts. Additionally, non-native English writers may deploy the hedges less flexibly than their native English writers. However, this finding is partially contradictory with that of Nasiri (2012) who found that both American and Iranian writers had similar use of hedges in Civil Engineering RAs. This may be due to the fact that the field of Civil Engineering is a hard science, so the use of hedge may not be common deployed in the studied RAs.

Regarding the hedge categories in the R-D section of English AL RAs, it was found out that the categories of hedges were similarly distributed in the R-D section of English AL RAs written by both Vietnamese and foreign writers. The Modal auxiliaries were most employed, followed by Epistemic Lexical verbs. This finding resonated with that of Tran and Duong (2013) who have found that hedges in forms of Modal auxiliaries were most used in the R-D section of English AL and Chemical Engineering RAs. Nonetheless, this finding was inconsistent with that of Farrokhi and Emami (2008) when their finding showed that Modal auxiliaries were not used the most in Electrical Engineering and English AL RAs by both native English and non-native English writers. This may be due to the scope of the study. This study and Tran and Duong's (2013) study focused only on the R-D section, while Farrokhi and Emami's (2008) study analyzed the hedge use in the four main components of RAs.

Another major finding is that the functions of hedges which were similarly deployed in the R-D section of English AL RAs by Vietnamese and foreign writers. The most used function of hedges was Reliability hedges, and the least one belonged to Reader-oriented hedges. This finding was corroborated with that of Nguyen (2018) which scrutinized the use of hedges in RAs written by Vietnamese writers, and that of Musa (2014) which analyzed the functions of hedges in English and Chemistry Masters' theses written by Ghanaian students whose English is an official language in their country. There are some plausible explanations for this finding. First, although the AL belongs to the soft science, writers in this study may attempt to use Reliability hedges to increase the degree of their confidence which could result in the validity of their claims. Second, the use of Reader-oriented hedges is to facilitate the effective communication between writers and readers (Hyland, 1996a), but the RA and Master's thesis are two genres of the academic writing. Therefore, one of the features of the academic writing is that the language use should be formal and impersonal (Tiersma, 2008).

\section{CONCLUSION}

This study has confirmed the norms and practices of the discipline of AL, a soft science. The use of hedges in the RD section in English AL RAs is common among scholars who are non-native English writers regardless of their unique characteristics and culture-bound. Both Vietnamese and foreigners in this study tend to use hedges in terms of frequency, types and functions in similar ways. Some pedagogical implications are made. First of all, the teaching of academic research writing should highlight the writing convention of different disciples and show their differences. Additionally, the importance of hedging and its use in the field of soft science should be emphasized as hedging is one of the useful tools in negotiating the meaning and creating a room for different interpretations.

Some limitations are still found in this study. This study focuses only on the use of hedges in one discipline between Vietnamese and foreigners, English AL, so the further extensive study may get involved in analyzing more variables (e.g., boosters) in RAs across different disciplines. Besides, there are different categories and functions of hedges, but this study adapted the categories and functions of hedges. Thus, the future study can examine the use of hedges within different categories and functions of hedges in order to see if there are any similarities or differences or not.

\section{REFERENCES}

[1] Bazerman, C. (1988). Shaping written knowledge. Wisconsin: Wisconsin University Press.

[2] Basturkmen, H. (2012). A Genre-based investigation of discussion sections of research article in dentistry and disciplinary variation. Journal of English for Academic Purpose, 11, 134-144.

[3] Crompton, P. (1997). Hedging in academic writing: Some theoretical problem. English for Specific Purposes, 16(4), $271-287$.

[4] Farrokhi, F., \& Emami, S. (2008). Hedges and boosters in academic writing: Native vs. non-native research articles in applied linguistics and engineering. The Journal of Applied Linguistics, 1(2), 62-98.

[5] Hinkel, E. (2005). Hedging, inflating, and persuading. Applied Language Learning, 15(1\&2), 29-53.

[6] Hyland, K. (1998). Hedging in Scientific Research Articles. Amsterdam: John Benjamins. Retrieved from http://dx.doi.org/10.1075/pbns.54

[7] Hyland, K. (2000). Hedges, boosters and lexical invisibility: Noticing modifiers in academic texts. Language Awareness, 9(4), 179-197. https://doi.org/10.1080/09658410008667145

[8] Hyland, K. (2005). Metadiscourse. London: Continuum.

[9] Hyland, K. (2008). Persuasion, interaction and the construction of knowledge: representing self and others in research writing. International Journal of English Studies, 8(2), 1-23.

[10] Lakoff, G. (1972). Hedges: A study in meaning criteria and the logic of fuzzy concepts. Chicago Linguistic Society Papers, 8, $183-228$.

[11] Musa, A. (2014). Hedging in academic writing: A pragmatic analysis of English and Chemistry Masters' theses in Ghanaian University. English for Specific Purposes World, 42(15), 1-26. 
[12] Nasiri, S. (2012). Utilization of hedging devices by American and Iranian researchers in the field of Civil Engineering, International Journal of Linguistics, 4(2), 124-133. DOI: https://doi.org/10.5296/ijl.v4i2.1494

[13] Nguyen, A. T. (2018). The use of hedging devices in Applied Linguistics academic discourse: the case of reading in a foreign language and English language teaching research articles. VNU Journal of Foreign Studies, 34(5), 12-24. doi:10.25073/25252445/vnufs.4298

[14] Nguyen, Q. N., \& Nguyen, L. T. U. (2015). Types of hedges used by American and Vietnamese celebrity, VNU Journal of Science: Foreign Studies, 2(32), 32-41.

[15] Salager-Meyer, F. (1994). Hedges and textual communicative function in Medical English written discourse. English for Specific Purposes. 13(2), 149-171.

[16] Spacey, J. (2020, July 29). 7 Characteristics of Soft Science. Simplicable. Retrieved from: https://simplicable.com/en/softscience on 12 January 2021.

[17] Tiersma, P. (2008). The nature of legal language. In J. Gibbons \& M. T. Turell (Eds.), Dimensions of forensic linguistics (pp. 7-25). Amsterdam: John Benjamins Publishing Company.

[18] Tran, Q.T., \& Duong, M. T. (2013). Hedging: a comparative study of research article results and discussion section in Applied Linguistics and Chemical Engineering. English for Specific Purposes World, 14(41), 1-13.

[19] Varttala, T. A. (2001). Hedging in scientifically oriented discourse: Exploring variation according to discipline and intended audience. Unpublished Ph.D. dissertation, University of Tampere Yliopisto, Finland.

[20] Yagiz, O., \& Demir, C. (2015). A comparative study of boosting in academic texts: A contrastive rhetoric. International Journal of English Linguistics, 5(4), 12-28. doi:10.5539/ ijel. v5n4p12

Thao Quoc Tran is a lecturer of English language at the Faculty of English language, Ho Chi Minh City University of Technology (HUTECH), Vietnam. His research areas are discourse analysis, English language skills, teacher professional development and instructional design model.

Thiep Ba Tang is a teacher of English at Singapore International School located in Binh Duong City, Vietnam. His research interest is about discourse analysis and English language teaching methodology. 